\title{
Tolerant Pedagogic Space as a Condition of Non-Violence Position Education among Elementary School Pupils
}

\author{
Ekaterina V. Mokeyeva ${ }^{1}$, Venera G. Zakirova $^{1}$ \& Alfiya R. Masalimova ${ }^{1}$ \\ ${ }^{1}$ Kazan (Volga region) Federal University, Kazan, Russia \\ Correspondence: Ekaterina V. Mokeyeva, Kazan (Volga region) Federal University, Kremlyovskaya Street 18, \\ Kazan, 420008, Russia. E-mail: ledyanochka@mail.ru
}

Received: December 29, 2014

Accepted: January 22, 2015 Online Published: February 11, 2015

doi:10.5539/res.v7n4p216

URL: http://dx.doi.org/10.5539/res.v7n4p216

\begin{abstract}
The purpose of article is to justify the necessity of tolerant educational space creation at elementary school as condition of non-violence position education of elementary school pupils. Essential characteristics of pedagogical ensuring education of non-violence position among elementary school pupils are revealed in the article. The features of tolerant educational space creation as conditions of non-violence position education among elementary school pupils in teaching and educational process at elementary school are revealed. Materials of the article can be useful for tutors and teachers of elementary schools, and also for the researchers dealing with problems of non-violence pedagogics.
\end{abstract}

Keywords: tolerant pedagogic space, non-violence position, education, elementary school pupils

\section{Introduction}

The problem of creation of tolerant space for providing nonviolent interaction of all teaching and educational process subjects induced us to do the research that is important for the modern society. There are some reasons for that. First of all, it is the modernization of the Russian society assuming as a result the development of educational system in which the following priorities of education are allocated now:

- Making younger generation adaptation to modern reality of the market relations easier through education of such values as: responsibility for own welfare and for society wealth; development of the main social skills in the sphere of interaction with world around;

- Resistance to negative social processes: to alcoholism, drug addiction, tobacco smoking and criminality among youngsters;

- Support of new generation entering into the globalized world by the development of communicative skills among young people, ability of cross-cultural mutual understanding;

- Education of non-violence, prevention of asocial motives, and also timely correction of children's aggressive behavior, etc. (Antilogova, 2006; Bezyuleva, 2002; Andreeva, 1980; Shemshurina, 2000; Belkin, 2000).

In this regard the problem declared by us accumulates the actual importance of all called priorities and demands the development of the contents and forms of realizing it in practice. Thus, this article represents an attempt to reveal the problem of non-violence education among elementary school pupils properly.

\section{Methodological Framework}

The position of a non-violence is acceptance of another person; that means the initial orientation to the person and to his personal value; readiness to interact with the person, acknowledging his right for personal interests, the accounting of his features and possible difference from the others; acceptance of other person into the inner world and correlation of own behavior according to the other person's one.

Intrinsic aspects of a non-violence position include the following components:

- Social (tolerance to other people opinions, convictions and behavior, to criticism of actions by other people);

- Psychological (ability to psycho-emotional stability and adequate reaction to events and the phenomena under various difficult conditions);

- Humanistic (acceptance of another person; orientation to the person and his personal value; readiness to interact 
with the person; acknowledging his right for personal interests, etc.).

All these aspects gave the chance to define non-violence position as personal education which includes values, settings, motives; where the desire of the person to communicate with other people and with the world in general on a nonviolent basis by means of free choice, ability to make nonviolent actions and to show nonviolent resistance are expressed.

Formation of non-violence position represents integrative process with the following components: formation of psychological stability (achievement of balance between social adaptation of the person and his identifying); systems of positive settings (transfer of value orientations to a positive way of acceptance of world around distinctions); a complex of individual qualities (empathy indicating, peacefulness, cooperation, tendency to a dialogue, etc.); systems of personal and group values (achievement of resistance to a stress and the psycho-injuring factors, resistance to uncertainty, to the conflicts, to behavior deviations, etc.).

Making a start with the characteristic of aspects, we worked out the following definition of non-violence position formation among elementary school pupils as specially organized pedagogical process aimed at the pupils' development of peacefulness, goodwill, empathy, ability to interact with world around on the nonviolent principles based on conflict free relationship creation between people.

Realization of a certain complex of specific tasks with various forms and methods of their solution is necessary for non-violence position formation: 1) education of peacefulness among elementary school pupils, genius of a non-violence (training of ability to realize difficult situations, to find ways out from them without using force, to be active in peacekeeping in surrounding society);2) correction of pupils' aggressive behavior, education of humane attitude towards people, development of ability to make positive resolution of conflicts (formation of ability to think of others, to understand them, to cooperate with them, and also creation of the atmosphere of security and intolerance to the human relations humiliating the dignity of people among pupils in the conditions of children's community); 3) the humanization of adults - children system relationship including development of position of a non-violence that a teacher must have in relationship with children and change of the parents - children's relations character ( the child's freedom in educational process means that both the adult and the child is 'the carrier' of the content of education, and the object of education is only educational material).

\section{Materials and Methods}

Skilled and experimental work was carried out on the basis of Kazan secondary schools No. 167, No. 36, No. 37. 583 elementary school pupils, 27 teachers, 401 parents took part in carrying out the experiment.

Carrying out experiment was preceded by drawing up the working program which logically consisted of the following:

- To reveal the initial level of tolerant consciousness formation among elementary school pupils;

- To realize the experimental program which purpose is to form position of a non-violence among pupils;

- To reveal changes which resulted after introduction of this program.

The research was carried out as at the level of the general improvement of all complex of the allocated pedagogical conditions as at the level of individual work with pupils, teachers and parents. During the experiment we created 2 control groups (CG1-1A a class - a person; CG2-1B a class - a person) and 2 experimental groups (EG1-1B a class - a person; EG2-1G a class-a person). The experimental part of research was divided into three stages: stating, forming and control. The name of each part of experimental work reflects a problem which was solved to the end of a certain period completely. At the first stage the stating experiment with carrying out primary diagnostics was organized. At the forming stage of psychological and pedagogical work with parents and children's position of a non-violence formation among primary school pupils was carried out. Statistical and mathematical processing of the obtained data was carried out at a control stage of the experiment.

The technique, approved in pedagogics and psychology, was applied in experimental work: the technique of tolerant consciousness measurement adapted for elementary school pupils by Stepanov and Stepanova (2007), "Diagnostics of typical features of preschoolers interaction with elementary school pupils", a technique of identification of cultural levels formation of elementary school pupils' communication by Ovcharova (2002), a technique of diagnostics of ability to empathy by A. Mekhrabiyen and N. Epstein; "Diagnostics of teacher's focus on educational and disciplinary or personal model of interaction with pupils", "Diagnostics of parents' attitude towards their children" (Varga \& Stolin, 1988).

To determine the level of pupils tolerant consciousness we used the questionnaire of personal growth developed 
by P. V. Stepanov (that allows revealing of character of the value attitude of pupils to the Motherland, to the Earth, to Peace, to work, to culture, to knowledge, to other people, to their health, to their inner world, to themselves (Stepanov, 2009). We were interested in results of the seventh scale in this research-the indicators of the value attitudes of pupils towards other people. We determined the following levels by this indicator: stable and negative, situational and negative; situational and positive and steady and positive attitude.

The technique "Diagnostics of typical features of preschooler's interaction with elementary school pupils" was carried out for the purpose of definition of a number of personal characteristics (friendliness, sociability, ability to build the relations, peacefulness and their opposite properties) two of which are the most important for us. They are difficulties in communication and hostility which are estimated in certain parameters. Set of parameters makes symptomatic complex. This technique consists of two parts. At first the elementary school teacher was offered to estimate the following qualities of elementary school pupils on a four-point scale: sociability, ability to build the relations with classmates, friendliness, peacefulness, and then each pupil performed independently a task from " $\mathrm{A}$ house - a tree - a person" test (HTP) at a drawing lesson. After carrying out testing we counted a score, and defined types of children's interaction: the sociable and friendly (SF); the sociable and hostile (SH); the unsociable and friendly (UF); the unsociable and hostile (UH).

\section{Results and Discussions}

At the stating stage OER unsociable friendly type of communication prevailed, unsociable hostile and sociable hostile communication types were expressed as well which have no fruitful character in the context of a position of a non-violence formation among pupils.

We determined levels of a non-violence position formation among children with the help of projective test "Nonexistent Animal". The research found out that the peacefulness sign (12\%) is shown among children to less extant. Most of children understand the word "peace" as lack of war or peaceful life, and the understanding of "peace" as peaceful coexistence as a result of cooperation of people for the sake of the world is available only to some pupils. Mostly such signs as refusal of violence application (66.7\%), negative attitude to violence $(88.9 \%)$ were shown. However supervision over children showed that children don't refuse violence in critical situations, sometimes they show moral indifference. It testifies that knowledge of children's correct behavior hasn't turned into skills.

Further the forming experiment on transfer from a potential form of non-violence position development among elementary school pupils to the actual was undertaken. In our opinion formation of non-violence position among elementary school pupils has to be carried out on a formula: "parents + children + teacher". Actions which parents take part in, are a good example of interaction of two most important child life factors the school and the family. They combine the efforts in the educational process directed at education of the open -minded, impartial attitude towards human variety.

The next diagnostics of the valuable attitude of pupils towards other people showed positive dynamics of the steady and positive attitude towards other person among pupils of experimental groups. We tried to reduce to zero the steady negative attitude and to decrease situational and negative attitude to $6 \%$ and $7 \%$. There were some positive changes in control groups as well, however they have no significant character. Dynamics of change of the value attitude towards other people before and after OER is presented in Figure 1. 


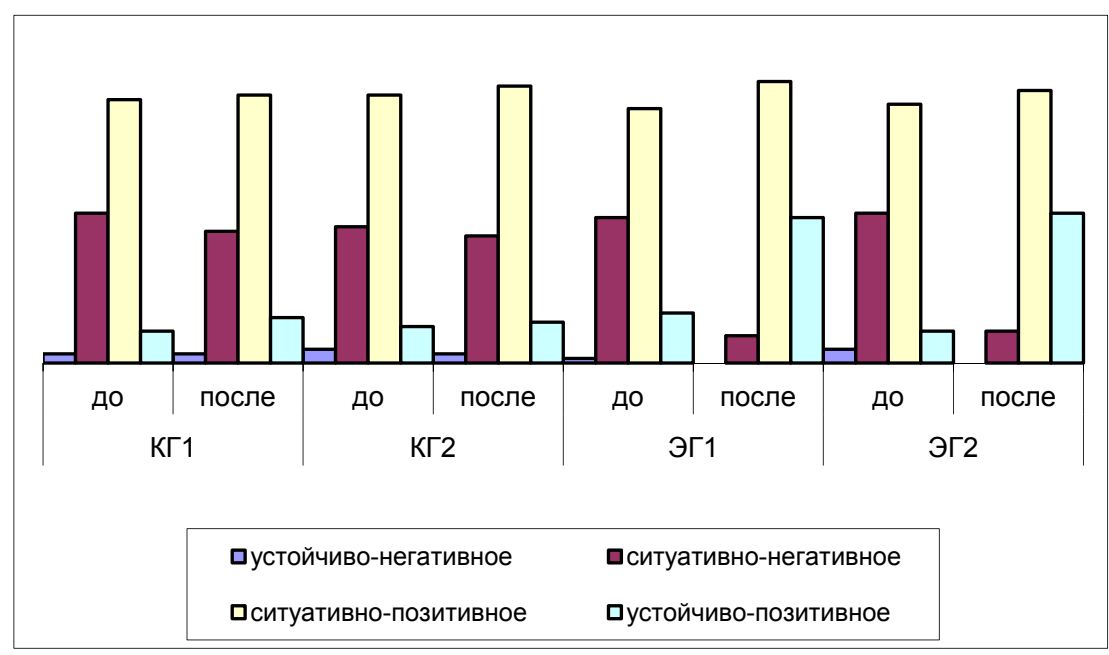

Figure 1. Dynamics of the value relation change towards other people before and after OER

The repeated inspection of typical features of children interaction showed the following: the same four types of interaction of elementary school pupils (sociable and friendly, sociable and hostile, unsociable and friendly and unsociable and hostile are observed), however, in comparison with initial results, there are changes: $52 \%$ and 50\% of pupils show sociable and friendly type of interaction (at the stating stage this type was shown by $23 \%$ and $24 \%$ of pupils). There were also changes in sociable hostilely type of interaction: these indicators decreased both in control, and in experimental groups. An explanation for this phenomenon can be that the stating experiment was made in the first grade when the kids' interpersonal relations weren't formed yet. The third year pupils had already formed relationship when check experiment was made. At the same time it should be noted that though this indicator decreased a little, nevertheless it testifies the existence of groups within the grades which often stand up against each other. Indicators of the unsociable and friendly relations of children are also decreased. It testifies positive results of the forming experiment. Dynamics of average values of type change of children interaction before and after OER is presented in Figure 2.

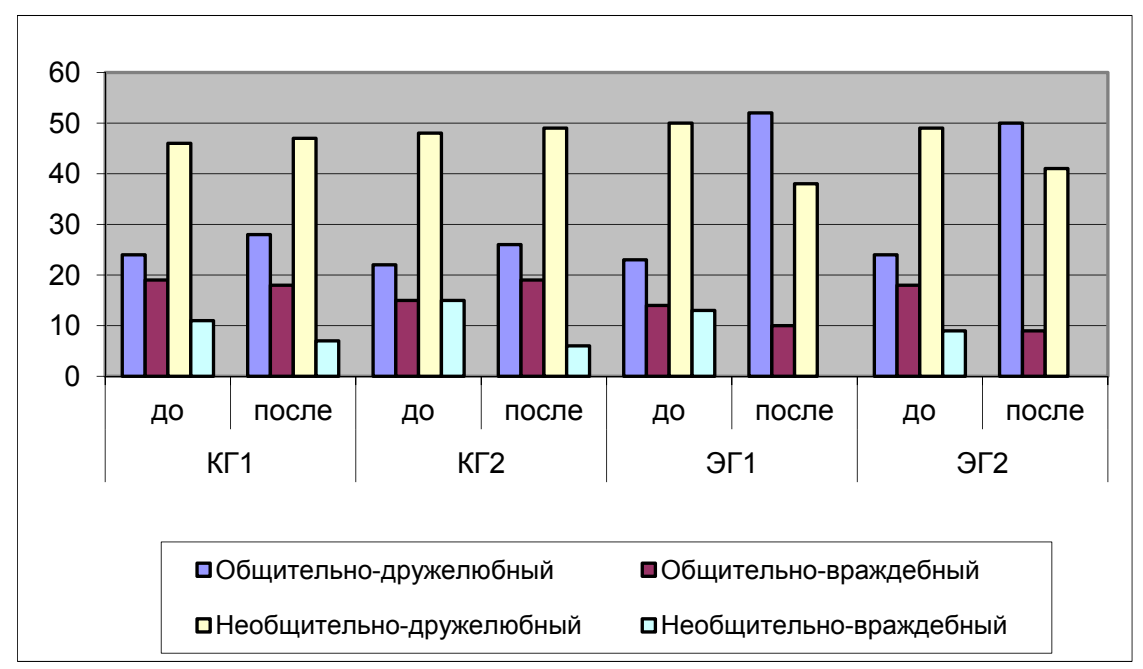

Figure 2. Dynamics of average values of types change of children interactions before and after OER

During the repeated carrying out a technique "The nonexistent animal" it was established: the sign of peacefulness was shown by $44.4 \%$ of children, refusal of violence application-by $78 \%$ of examinees, and such sign as negative attitude towards violence was shown by $92.2 \%$ of pupils.

Supervision over children in teaching and educational process showed that the number of quarrels and conflicts decreased in experimental groups. Children tried to communicate, to concede each other friendly and to resolve 
disputes independently. It is very important that during conversations with children we found: they began to realize that other children, as well as they, have the steady, independent characters and belief they have to reckon with. It is shown in empathy to the classmates and in requirement of emotional support. All this allows to state that the correctional developing program which we carried out with children, was effective in non-violence position formation among children of elementary school age.

\section{Conclusion}

Thus, the work directed at formation of non-violence position of elementary school pupils can be effective in the conditions of specially organized tolerant educational space of elementary school. Its main characteristics are: a community of all subjects of interaction views towards the problems of children. There should also exist common system of forms, methods, receptions and means of the organization of activity of elementary school pupils while educating their peacefulness. They must have goodwill, aspiration in the nonviolent way to resolve the arising conflicts. It is revealed that the tolerant educational space provides conditions of the value attitudes formation of children towards other people, empathy, refusal of violence and aggression. The tolerant educational space of elementary school promotes maintenance of the favorable psychological atmosphere in a grade and a positive emotional genius. It allows providing of children education in the genius of peace.

\section{Acknowledgments}

The work is performed according to the Russian Government Program of Competitive Growth of Kazan Federal University

\section{References}

Andreeva, Y. (1980). Social psychology text (p. 416). Moscow: Mosk, University Press.

Antilogova, L. N. (2006). Foundations of modern etiquette (p. 134). Moscow.

Belkin, A. S. (2000). Basics of age pedagogy (p. 192). M .: Izd.Dom “Akade9miya”.

Bezyuleva, G. V. (2002). Tolerance in pedagogy text (p. 228). Moscow: Academy of Professional Education.

Ovcharova, R. V. (2002). Handbook of school psychologist (p. 87). Moscow.

Shemshurina, A. I. (2000). Ethical grammar in elementary classes (p. 96). Moscow.

Stepanov, P. V. (2009). Development of the school as an educational system (p. 240). Moscow: Center "Teaching Search".

Stepanov, P. V., \& Stepanova, I. V. (2007). Diagnosis, analysis and planning process of education at the school (p. 96). Moscow: Center "Teaching Search".

Varga, A. J., \& Stolin, V. V. (1988). The questionnaire parental relations Varga-Stalina (ORI).

\section{Copyrights}

Copyright for this article is retained by the author(s), with first publication rights granted to the journal. This is an open-access article distributed under the terms and conditions of the Creative Commons Attribution license (http://creativecommons.org/licenses/by/3.0/). 